\title{
Reason Analysis and Improvement Measures for Employment Difficulty of College Students
}

\author{
Dong Zhang and Shuang Zhang \\ The Engineering \& Technical College of Chengdu University of Technology, Leshan, Sichuan, China, 999078 \\ zd7585@qq.com
}

\begin{abstract}
Nowadays, the education in China has experienced unprecedented development; the number of college students has increased several times over, accompanied by the problem of "employment difficulty" for college students. First, the conflict should be comprehensively analyzed, including national policies, the education system, the employment mechanism and individual reasons. Second, their subjective initiative should come into play. In order to solve this problem, the corresponding measures should be found out.
\end{abstract}

Keyword-College Students, Employment, Reason, Measure;

\section{INTRODUCTION}

At present, employment difficulty of college students is not a fresh theme, but it is a thought provoking thing. Every year many college students cannot get jobs, thus this brings many unstable factors to the society, and meanwhile it affects development of the society. Therefore, how to solve employment difficulty of college students become a hot spot of the whole society.

TABLE I. C CURRENT EMPLOYMENT SITUATION OF COLLEGE STUDENTS IN CHINA

\begin{tabular}{|l|l|}
\hline Year & Graduate Number \\
\hline 2003 & 2120000 \\
\hline 2004 & 2800000 \\
\hline 2005 & 3380000 \\
\hline 2006 & 4130000 \\
\hline 2007 & 4950000 \\
\hline 2008 & 5590000 \\
\hline 2009 & 6110000 \\
\hline 2010 & 6310000 \\
\hline 2011 & 6710000 \\
\hline 2012 & 6800000 \\
\hline
\end{tabular}

Since the late 1990s, Chinese economy has developed steadily and rapidly. In order to adapt to the demand for high-level talents in rapid economic development, the enrollment scale of colleges and universities is further expanded. In 2003, the first peak employment of college students since enrollment expansion in Chinese colleges and universities came; and there are 2.12 million university graduates through the country, increased by $46.2 \%$ than those $(1.45$ million) in 2002. The number grows to 6.80 million this year. With the unceasing increase of the number of college graduates, the first employment rate of graduates declines gradually, and college students who cannot find jobs become more and more each year. According to the statistics of education departments, in recent years the number of unemployed university graduates is continuously rising. In 2001, there are 340 thousand unemployed persons, 520 thousand in 2003, 790 thousand in 2005 and 1.44 million in 2007. In recent years, the first employment rate has always remained at around $70 \%$. Therefore, the accumulated underemployed college students become more and more.

\section{REASON ANALYSIS OF EMPLOYMENT DIFFICULTY OF COLLEGE STUDENTS IN CHINA}

\section{A. Government Aspect}

\section{1) Household Registration System}

The household registration system in our country has a standard duality structure, which caused much social injustice, so the economy also has the duality. The income per capita in underdeveloped areas is relatively lower; the social security system cannot meet requirements, and there are few development opportunities there. Thus most of college graduates choose to find jobs in the economically developed city.

2) Adjustment of Industrial Structure

Now China is undergoing a process of constantly adjusting her industrial structure. Adjustment of the industrial structure includes "balancing process of industrial structure" and "upgrading process of changing economic development mode and structure", and the above two points will produce a direct and important impact on employment. ${ }^{[2]}$

3) Unbalanced Supply and Demand Structure of Personnel Market

On the one hand, after the socialist market economic system was established, the government gradually set up the employment system of "Independent choosing profession and two-way selection". New undergraduates may not adapt to the two-way selection very much. While the government did not complete ideological publicity and political encouragement. Additionally, the strength of economic regulation and control measures is insufficient, so the macro-control appears weak unavoidably. Consequently, 
this will give rise to the problem of "there are vacant job positions and many persons cannot get jobs".

"Nobody has a job; someone didn't work" problems.

4) Unsound Legal System and Imperfect Employment Market for University Students

In the employment market, for example, gender discrimination, age discrimination, education discrimination, regional or domicile discrimination and chronic disease patients such as hepatitis B being discriminated are often seen. The above phenomena deviate from requirements of the market economy in optimizing allocation of labor resources and distort the labor market, and dissimilate the job market to a certain extent. Some latent employment rules are still popular, which declines effective matching between supply and demand of labor.

\section{B. Social Cause : Conceptual Problems of Employers in Employment}

Recruiting companies set up higher degree threshold when choosing talents and only the education degree is taken as the judgment basis, and excessive attention is paid to the diploma. Many employers do not match their demand with personnel selection objectively, but over-emphasize high academic qualifications and higher degree. Even some employers have the complex of elite schools but do not consider personal ability too much, and state clearly that "Graduates from elite schools are preferred". In addition, employers think highly of working experience in the employment, and hope that college students can change enterprises when they begin to work, while inadequate experience is the biggest disadvantage of the graduating college students, they often cannot satisfy the requirement of employers. Some employers have serious gender discrimination, because they consider women's physiological, marriage and fertility problems, so they are unwilling to recruit female college students; some still have the regional discrimination, so this make a lot of outstanding university students suffer employment discrimination, and they cannot give play to their own professional competency and wisdom.

\section{Colleges and Universities' Responsibility}

1) Utilitarian Major Setup, Old-fashioned Curriculum Provision, and Ambiguous School-running Orientation

Many colleges and universities lack thorough investigation and scientific prediction for social demand and employment prospects in setting up new majors, only keen to less investment. Outdated knowledge and skills learned by students are severely disconnect with development requirements of employers and the society. In the meantime, the school-running orientation is ambiguous and the personnel training mode is lagging. The effect of the ordinary university level evaluation system on universities' talent cultivation is obviously greater than the directing role of the job market. In general, universities' talent cultivation lags the market demand, the education and teaching process lag behind the employment guidance and the enrollment is separated from the employment.

\section{2) College Education Content Prefers Urban Service}

At present, the education content of most colleges and universities in our country is characterized by providing service for cities, and this makes the educators form the specific urban human capital. But the specific human capital probably lack scope for their abilities in the countryside. The higher the degree is, the harder the matched position is found in rural areas. Meanwhile, the current education system is located in the city, so employment in the countryside has no comparative advantage. For this reason, the existence of the specific urban human capital virtually strengthens the university students' employment preference for the city.

3) Blind Enrollment Expansion Leads to Product Quality Reduction and Unmatched Supply and Demand of Talents

The investigation showed that employment difficulty due to the weak ""professional skills" accounts for $48.41 \%$, standing first in the list. Therefore, college students who feel their abilities are not strong and their majors are not professional make up nearly one half. Enrollment expansion is not wrong, but the matching education resource is not put in place in time, that is, this is a kind of blind and irrational enrollment expansion. This makes the teaching level drop and talent quality has serious defects, so as not to meet social demand. In the meanwhile, this causes structural unemployment of college students.

\section{Personal Reasons of Students}

1) College Students' Employment Orientation Separates from the Social Reality and they are Unwilling to work

Another statements spreading among college students is to prefer a bed in the big city to a house in the small city. This reflects the attitude of college students that they are unwilling to work at the basic level and in the rural areas.

A series of surveys are as follows:

TABLE II SuRVEY ON “DESIRABLE WORKING REGION"

\begin{tabular}{|c|c|c|c|c|c|}
\hline $\begin{array}{l}\text { Desirable } \\
\text { working location }\end{array}$ & Big city & $\begin{array}{l}\text { Economically } \\
\text { developed area }\end{array}$ & $\begin{array}{l}\text { Close to } \\
\text { home }\end{array}$ & $\begin{array}{l}\text { Medium and } \\
\text { small town }\end{array}$ & Indifferent \\
\hline Proportion & $58.05 \%$ & $11.66 \%$ & $6.71 \%$ & $4.96 \%$ & $3.18 \%$ \\
\hline
\end{tabular}


TABLE III SURVEY ON "GO TO GRASS-ROOTS ORGANIZATION"

\begin{tabular}{|l|l|l|l|l|}
\hline Attitude & Decided to & Will not go & Probably & Leave out of consideration \\
\hline Proportion & $6.01 \%$ & $5.30 \%$ & $56.18 \%$ & $21.55 \%$ \\
\hline
\end{tabular}

TABLE IV SUPPORT THE WEST OR BECOME A VILLAGE OFFICIAL, ARE YOU WILLING TO DO THIS JOB??"

\begin{tabular}{|l|c|c|c|}
\hline Attitude & Willing & Unwilling & Leave out of consideration \\
\hline Proportion & $35.34 \%$ & $20.49 \%$ & $34.98 \%$ \\
\hline
\end{tabular}

In fact, "Leave out of consideration" means that he or she is unwilling. It is thus clear that most people are unwilling to work in the grass-roots organizations and the places with tough conditions.

Survey on "If job hunting is difficult, do you can accept the enterprises at the small and medium-sized town or township enterprises"

\begin{tabular}{|l|l|c|c|}
\hline Attitude & Willing & May accept if no other opportunity is supplied & Never accept \\
\hline Proportion & $32.86 \%$ & $50.53 \%$ & $6.17 \%$ \\
\hline
\end{tabular}

These data reflect the employment of college students is basically consistent with the value orientation, volunteered to go to the west, to go to the countryside, not a lot of people go to basic conditions such as local, even want to go to is forced to helpless, very few people want to go to the heart. And realistic society is in the west, rural, grassroots have more chances of employment. Visible college students' employment orientation deviation of social reality is the source of the university students' employment difficult ideas.

\section{2) Inaccurate Employment Orientation}

College students lack objective and scientific self-understanding and often overestimate their own abilities. Most of the students are indifferent to the social demand have no clear career goals, and cannot combine their own majors and national development. Many college students can't objectively know themselves and the environment correctly during choosing a career, and unduly pursue the vocations beyond their own quality and the conditions provided by the society, and lack correct orientation in job selection.

3) Weak Core Competitiveness and Low Comprehensive Quality

Praha lad and Hamel thought that "the core competitiveness refers to the competitive and unique knowledge and skill difficult to be imitated by competitors". Core competence not only reflects the comprehensive quality but also emphasizes competitiveness, which will be discovered through the social inspection. Now main problems include: innovation and problem solving ability is not strong as well as the communication ability and the team cooperation spirit, and their professional knowledge is not solid, without positive and good mental state.

\section{MEASURES}

\section{A. Government Aspect}

A. The employment mechanism of university students should be established and improved to promote employment. Various policies should be issued to encourage rational flow of trained people, so as to eliminate restrictions on free employment of graduates such as family register, personnel archives and other obstacles, to strengthen guidance for supporting the border areas and agriculture as well as support agree, finally to promote employment of university graduates.

$B$. The government should pay attention to coordinated growth of economy and employment. Economic development is not to blindly pursue GDP growth, but to improve the people's welfare. Our country should build the public policy system with college students' employment as the core, and make efforts to expand employment; sometimes the economic growth rate should also be sacrificed to ensure full employment of college students.

$C$. The government should strengthen guidance and regulation for enterprises. Enterprises are the first large base accommodates college students, so the government should lay down the reasonable economic preferential policies to guide enterprises to absorb employment, standardize enterprises' behavior via laws, regulations and other policies, so as to solve the employment problem.

\section{B. Universities Aspect}

1. The market economy should be utilized to promote and speed up reform of the higher education system, to transform traditional majors and foundation subjects, and to intensify building of emerging industries and pillar industries, to reduce the major number and professional curriculum, to expand the professional knowledge scope, so as to optimize major setup. In personnel training, colleges and universities should break the disciplinary barrier, strengthen interdisciplinary integration, and establish the training system combining learning and application. Improving college students' practical ability and professional quality is decisive to solve the employment problem of university students based on enterprise demand; in addition, cultivation of inter-disciplinary talents should be enhanced.

2. The students' quality should be overall improved. 
While promoting reform of the education system and the talent training scheme, colleges and universities must strictly emphasize the education quality and pay attention to combining theory study and practice in students' learning. Educating should be performed prior to teaching; colleges and universities should increase investment in educating and strengthen guidance. Colleges and universities should also strengthen career planning guidance for students, and let students arrange targeted university life and promote students' growth and success.

\section{Employer Aspect}

1. Employers should change the concept of employing talents. Employers should change the prejudice against new graduates. Employers should respect the university graduates and make an objective and comprehensive evaluation of contemporary college students; they cannot think all students are like that because some of the graduates behave badly in the employer organizations. The employers should treat every university student applying for a job in a fair and objective attitude, but should blindly not pursue graduates from famous universities and highly educated graduates.

2. Employers should undertake the social responsibility. Employers should not blindly pursue economic benefit, but should assume more social responsibilities. College students is the talents cultivated through great efforts of our country, so employers should actively accept college graduates at all levels and provide a stage for them to exploit their talents, and assume social responsibility.

\section{Student Aspect}

1. Students should calm the mind and strive to improve their own quality. On the one hand, they should develop good habits and noble quality. Good moral quality and behavior is the basis of individual success. On the other hand, college students should not only learn professional knowledge seriously, also improve their operational ability and organization ability. They should set up the team spirit, adapt to the rapid development of modern society and throw themselves into social practice. While improving the moral quality, professional knowledge and practical skills, college students should also improve their physical quality and the psychological quality, and strive to achieve transformation from senior high school students to college students, from students to social men, to young, promising and responsible youth, so as to lay a solid basis for their own employment.
2. College students should set right mental state and sets up the new employment concept. College students should get rid of the thought of "God's favored one" to enter the job market in a low-profile way; they should never think yourself above business to lose good employment opportunities. They should not blindly pursue "talents should go to the southeast". Metropolitan employment pressure is larger, but the urban and rural grassroots organizations provide a large field for college students to exploit their talents.

\section{CONCLUSION}

We are a new generation of college students, so we should develop our own ability from now on. After all, in the contradiction, we own reason is the main aspect of the contradiction. Therefore, in order to better solve the employment problem, we should give full play to our subjective initiative. We should change our employment attitude, set up scientific world view, enhance our innovation capability, improve our own competitive power, pay attention to quantitative accumulation, but we should not become the person who thinks himself over business, so as to make ourselves able to better accept selection of the society. But the secondary aspect of the contradiction also needs to be well resolved. Therefore, the government, education institutions and the society should take responsive measures. Only in this way, the existing employment problem can be solved. This is the result all expect.

\section{REFERENCE}

[1] ACT. (1997). ACT Assessment technical manual. Iowa City, IA: Author.

[2] ACT. (2002). ACT Assessment user handbook. Iowa City, IA: Author.

[3] Adelman, C. (1999). Answers in the tool box: Academic intensity, attendance patterns, and bachelor's degree attainment Washington, DC: U.S. Department of Education.

[4] Asera, R. (1998). Supporting student persistence. Black Issues in Higher Education, 15(10), 104.

[5] Barfield, M. A., \& Beaulieu, L. J. (1999). The changing nature of work in the south: The polarization of tomorrow's workforce. Mississippi State, MS: Mississippi State University, Southern Rural Development Center.

[6] Barefoot, B., Fidler, D., Gardner, J., Moore, P., \& Roberts, M. (1999). A natural linkage: The first-year seminar and the learning community. In J. H. Levine (Ed.),Learning communities: New structures, new partnerships for learning(Monograph No. 26) (pp. 77-86). Columbia, SC: University of South Carolina,National Resource Center for the First-Year Experience and Students inTransition.

[7] Bean, J. P. (1980). Dropouts and turnover: The synthesis and test of a causal model ofstudent attrition. Research in Higher Education, 12(2), 155-187 